\title{
Role of human capital in the promotion of technological progress, economic growth and development in Africa: A case study of Kenya
}

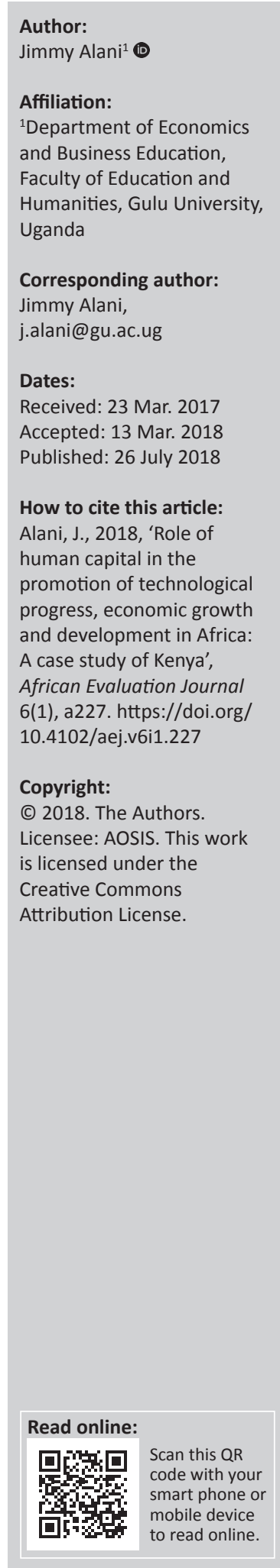

Background: This article evaluates the role of human capital in the promotion of technological progress, economic growth and development in Africa by focusing on the case of Kenya.

Objectives: The overall objective of this article was to evaluate the effects of human capital on technological progress, economic growth and development in Kenya over the period between 1971 and 2014.

Method: In this article, human capital was measured by human capital index defined as the ratio of current level of human capital in the national economy to the level of human capital 2 years ago. In particular, human capital in the broad sense was estimated by computing the ratio between 2 years of the hypotenuse of capital and labour vectors, and this measure outperformed all the other measures of human capital by yielding very good regression results by way of the generalised least squares technique.

Results: Based on the econometric and statistical analyses, human capital in Kenya was found to have had a positive influence on economic growth in the long run. Human capital was also found to have had a positive influence on labour in the long run.

Conclusion: Both human capital formation and technological progress should be given priority in the promotion of economic growth and development in Kenya rather than merely increasing the productivity of either capital or labour. Capital accumulation and labour generation should also be encouraged because increase in the two variables always under normal circumstances results in economic growth and development.

\section{Introduction}

\section{Background}

Human capital is the stock of skills that the labour force possesses. It encompasses the idea that there are investments in people (e.g. education, training and health) and that these investments increase an individual's productivity. Modern theories of economic growth emphasise human capital. According to these theories, human capital can promote growth by stimulating technical progress, inventions and innovations. Technology refers to knowledge creation and application and its augmentation of the labour input through education and training (Jones \& Manuelli 1990; Lucas 1988; Romer 1986). Several empirical studies have endeavoured to establish the relationship between human capital and economic growth. In many of those studies, human capital was found to enhance economic growth and development. However, in some few cases, human capital has failed to stimulate economic growth and development. Therefore, the hypothesis that human capital plays a significant role in technological progress, economic growth and development has not been empirically validated (Oxley, Le \& Gibson 2008).

The overall objective of this article is to investigate the effects of human capital and technological progress on economic growth and development of Kenya during the period of 1971 to 2014. The research questions used to guide our investigation are as follows:

- To what extent does human capital affect economic growth of a country?

- Through which channels does human capital influence economic growth?

- Which measure of human capital offers better results when applied to data?

In the process of evaluating the broad influence of human capital on economic growth, the study found that the measure of human capital broadly in terms of ratios of hypotenuse of capital and labour vectors outperformed all the other measures of human capital and yielded very good 
regression results by way of the generalised least squares (GLS) method. This article agrees with the human capital theory that: 'investments in human capital raise labour productivity'. Therefore, in the case of Kenya we find that investments in human capital raised labour productivity via increasing technical progress and consequently caused economic growth. However, growth in human capital has negative influence on economic growth when it affects output via productivity of either capital or labour. Hence, rapid technological progress would enable Kenya in particular to skip some of the development stages some countries have successfully leapfrogged in their development process.

\section{Literature review}

Human capital is important for economic growth. Human capital consists of the following attributes: natural ability, innate and acquired skills, knowledge, experience, talent and inventiveness. In human capital formation, present expenditures are expected to yield future streams of benefits. Human capital formation is driven by expenditures on health, safety, science, research and education. Regardless of any national economy, productivity depends on the following: the level of work organisation, technology, technical support, the level of education, motivation of employees to increase their performance, and also the natural and soil conditions. Employment generation, capital accumulation and economic growth are caused by labour productivity and technical progress. Most importantly, nowadays education is responsible for rapid production and extensive introduction of technical innovations. Education (i.e. human capital formation) contributes to the technological progress by increasing the value of the human capital and overall economic growth. Within the 1980s and 1990s, the latest modern economic growth theories were formulated. In these theories, human capital is taken to be one of the key factors of economic growth. These new growth theories are based on the assumption that the production function is affected by labour and capital, as well as by education, improving the quality of labour and capital and better infrastructure. In each and every nation, production of goods and services requires both physical and human capital. Physical capital is composed of machines, the equipment and the technologies. Human capital consists of natural (inborn) or acquired (obtained) knowledge, competencies, skills and experiences of the individuals (Kucharcikova 2011).

Broadly, the concept of human capital is the mixture of human capital and physical capital (Boldizzoni 2008; Kwon 2009). And it is this concept that this article uses to compute the human capital index (HCI). This article takes physical capital to be part and parcel of human capital because physical capital is a result of human creativity. And it is also because investment of physical capital is spent on human capital in terms of education and training (Kwon 2009; Little 2003).

This article, therefore, views human capital as broad human capital (physical capital plus human capital) not the narrow human capital, the one that scholars normally write about. Human capital formation could also be driven by scientific research in human capital formation by making investigations on how best to strategically undertake investments in health, education, housing, food, security and overall infrastructure in order to optimally stimulate technological advancement, economic growth and development. That is because scientific research and education as well as other sectors behave like industries to produce new forms of capital themselves. As a result, scientific research could produce two forms of capital: those that could be transformed into new skills and human capabilities of economic value (human capital), and those that could be transformed into new materials of economic value (nonhuman capital), that is, physical capital (Schultz 1971). Therefore, growth in human capital, in particular growth in scientific knowledge, has raised the productivity of labour and increased the value of education and training as embodied in scientists, technicians, managers and other workers (Becker 1993; Coleman 1993; Mincer 1958).

Macroeconomic and microeconomic approaches are the two basic approaches to human capital identified in economic theory. The macroeconomic approach is used in this article for the understanding of human capital as applied in the economy of Kenya in particular. The microeconomic approach is classified under business economics. In management, human capital is viewed as a business resource or asset which forms part of the market value of the company. In the macroeconomic approach, human capital is viewed as one of the sources of the economic growth. Economic growth can only be achieved through intensive and extensive use of the production factor which is usually embedded in the gross domestic product (GDP) of a nation (Alika Aibieyi 2014; Kucharcikova 2011).

Extensive economic growth comes as a result of increasing the quantity of used production factors, basically land, labour and capital. These are well-known basic factors of production in economics. Capital is one of the factors of production. Capital was the decisive factor of production to achieve growth in the period before the Industrial Revolution. Nowadays, most of the workforce are employed in agriculture in many developing countries. When economic growth is too high, capital as well as the natural resources is depleted. Labour is another factor of production responsible for economic growth. Increase in labour force leads to economic growth through demographic trends, amount of labour force, scientific and technical progress status, the social division of labour and labour productivity in various sectors. Nowadays, fully skilled workers for operation and maintenance require technologies. Increase in labour force could be achieved through training and retraining. In economics, capital includes things like buildings, machinery and equipment. Capital accumulation alters the ratio between production factors. Capital accumulation is increasingly being directed to education and research. In the 1980s, economists found it important to separate capital in terms of physical and human capital (Alika \& Aibieyi 2014; Kucharcikova 2011). 
According to Kucharcikova (2011), UNICEF, an organ of the United Nations, calls upon all governments of the world to ensure that $26 \%$ of the nation's budget is geared towards education development. Human capital includes natural ability, innate and acquired skills, knowledge, experience, talent and inventiveness. These characteristics are entirely components of the human capital. Increasing the value and effectiveness of human capital is possible through spending money now and reaping the expected benefits that will flow in future. Thus, in the short run, intensive economic growth is caused by increase in productivity. Increasing the value of human capital requires spending on things like health, safety, science, research and education (Alika \& Aibieyi 2014; Kucharcikova 2011). Human capital is influenced by the quality, efficiency and manner of combining production factors.

Intensive economic growth factors include technical progress and increase in productivity factors. The determinants of aggregate productivity are levels of: work organisation, technology, education, motivation and the natural and soil conditions (Alika \& Aibieyi 2014; Kucharcikova 2011).

In the era of rapid and extensive introduction of technical innovations, education is the most important factor. Education contributes to technological progress, productivity growth of factors of production and increasing the level of aggregate human capital and economic growth (Alika \& Aibieyi 2014; Kucharcikova 2011). It was education that contributed to economic growth and it accelerated growth in the 1950s and 1960s (Kucharcikova 2011). Although economic growth could be explained in terms of growth in physical capital and technological innovation, human capital is the principal cause (Alika \& Aibieyi 2014). Therefore, human capital is the only source of economic growth in a modern economy (Alika \& Aibieyi 2014; Schultz 1981).

Economists have recognised that people are an important component of the wealth of nations (Schultz 1961). All acquired and useful abilities of the inhabitants of a country form part of capital (Petty 1690; Schultz 1961; Smith 1776). This fact can be demonstrated using the power of England, by estimating the total human capital of that country to be $£ 520$ million or $£ 80$ per capita. Similarly, Farr (1853) estimated the average net human capital of an English agricultural labourer to be $£ 150$. In recent times because of the importance of application of knowledge in the economy, human capital has increasingly attracted both academic and public interest (Kiker 1966; Oxley et al. 2008). Human capital theory suggests that in any country, it is human capital (the knowledge and skills embodied in people) rather than physical capital that is important for economic prosperity.

In most Organization for Economic Cooperation and Development (OECD) countries, private and public investment in human capital, in the form of expenditure in education and training, accounts for over $10 \%$ of national income (Healy 1998). Understanding human capital is of great interest to politicians, economists and development strategists. In recent economic literature, interest in human capital focuses on economic growth. Traditionally, focus was on increasing economic growth by providing workers with more access to physical resources, like land, factories and machines (Oxley et al. 2008).

Modern theorists of economic growth emphasise the importance of human capital in spurring economic growth (Jones \& Manuelli 1990; Lucas 1988; Romer 1986). These theorists have opined that human capital can foster growth through stimulating technological creation, invention and innovation. To validate this claim, several empirical studies have attempted to establish the relationship between human capital and economic growth. Consequently, human capital has been found to enhance growth in some cases. In other empirical studies, results have failed to establish any positive relationship between human capital and economic growth. The hypothesis that human capital plays a significant role in the growth process has not been empirically validated. Yet, the major reason for the mixed evidence could be because of the fact that human capital has been poorly measured. Other researchers might have failed to identify the positive relationship because the proxies used did not capture key elements of human capital or because the data on the proxies were erroneous.

Consequently, measurement error might have accounted for the somewhat surprising finding that greater investment in human beings was not associated with faster economic growth. This concern with measurement error brought about the question that has occupied economists in the last several decades: how can we measure human capital adequately? Following the insights of Adam Smith, the creation of specialised labour is seen to require the use of scarce inputs, typically education or learning. This emphasis on education has led to a research agenda where human capital is estimated by some measure of school experience. But, it is only one of several approaches to the measurement of human capital (Oxley et al. 2008). Alternative methods have been built upon Smith, Ricardo and modern labour economics more generally. In particular, these measures of human capital are based on the cost of production or the expected earnings of heterogeneous labour. These approaches have a rich and long intellectual pedigree and the advantage of easily permitting monetary values to be assigned to the capital stock, thus enabling comparisons with other types of capital.

As usual, the impact that human capital has on economic growth is sensitive to the measures or proxies of human capital. But there is need to have an accurate and consistent measure of human capital, which can facilitate cross-sectional and temporal comparisons. Only when human capital is adequately and consistently measured, can we understand how it affects the growth process and how governments or firms can influence its quantity or quality. The need for a reliable measure of human capital is reinforced by the fact that even in countries where attempts are made to estimate 
the value of human capital, it is not yet standard practice for official statistical agencies to include human capital in their capital stock measures. This is a surprising omission because estimates of the value of human capital, as mentioned above, predate the formal development of National Accounts Statistics (Oxley et al. 2008).

Oxley et al. (2008) identify three general approaches to human capital measurement, cost-based, income-based and education-based measurement, and present a critical review of the theories and their applications to data from a range of countries. They found that different approaches based on cost, income and education were correlated. The models were connected because inputs in the human capital production process, such as costs of rearing and educating people, formed the basis for the costing method. The income method is built on individuals' earnings, but indicators such as literacy rates, school enrolment rates and average years of schooling have widely been used as education-based measures of human capital. There has been a radical change in the motivation behind human capital valuation. Early studies were more concerned with demonstrating the power of a nation, with estimating the money values of human loss from wars and plagues, and with developing accurate measures of human wealth in national accounts. Recently, the focus has switched to using human capital as a tool to explain economic growth across countries.

Besides driving the economic growth process, human capital plays a critical role in producing positive external effects such as enhanced self-esteem, enjoyment and development of individual capabilities, reduction in poverty and delinquency, and greater participation in community and in social and political affairs. But rarely has the impact of human capital on economic growth been empirically supported. The lack of empirical consensus arises because although approaches to human capital valuation build on sound theoretical underpinning, none of them is free from shortcomings. Each approach is more or less subjected to two types of measurement error: (1) the measure does not adequately reflect key elements of human capital and (2) data on the measure are of poor quality.

Therefore, proper measurement of human capital still remains a great challenge (Oxley et al. 2008). For instance, Eggoh, Houeninvo and Sossou (2015) used traditional cross-section and dynamic panel techniques, and found that public expenditures on education and health had negative effects on economic growth, but human capital stock indicators had slightly positive effects. They were right to have concluded that education and health expenditures had enhanced economic growth in the sample of African countries. However, they could have been wrong in blaming the negative effects on economic growth arising from education and health expenditures (i.e. human capital development) on government inefficiency, corruption, bureaucracy and underinvestment. Therefore, their mistake could have been because of some measurement errors. To untangle the measurement problems involving human capital and technological progress, this article has used the neoclassical production function with decreasing returns to scale, unlike most studies that have used constant returns to scale to estimate shares of capital and labour in the GDP. Using decreasing returns to scale parameters seems to be more realistic because the individual participants in the national economy, more often than not, are rational actors who always strive to gain the most out of their individual actions. Moreover, unlike in most studies, this article defines and measures human capital broadly, that is, in terms of quantity of both capital and labour.

\section{Method}

This article employs the Cobb-Douglas production framework (i.e. neoclassical production model) in both the theoretical and empirical analyses.

The analyses (i.e. evaluation) that this article undertakes are the effects (i.e. role) of human capital on technological progress, economic growth and development in Kenya between 1970 and 2014. The Cobb-Douglas production function is still one of the most important functions in the theoretical and empirical analyses of growth and productivity. The estimation of the parameters of aggregate production functions can be used in the determination (i.e. estimation or evaluation) of the effects (or role) of human capital on economic growth, development, technological change, productivity and labour. In macroeconomics, the essential tool for analysis is the empirical estimation of the aggregate production function. The production function estimation is also an important tool for making important theoretical constructs regarding variables such as potential output, level of technology, human capital, labour supply and capital. In the Cobb-Douglas production function meant for empirical analysis, the estimated regression could be expressed as: $Y_{t}=A_{t} K_{t}^{\alpha} L_{t}^{\beta}$, where $Y_{t^{\prime}} A_{t}, K_{t}, L_{t}$ represent aggregate output, labour and capital, respectively, $A$ is a constant and the elasticity or parameters are $\alpha$ for capital and $\beta$ for labour. The Cobb-Douglas production is simply derived as an algebraic transformation of the identity. This transformation gives rise to results that are estimates for $K$ and $L$ that could be estimated (Felipe \& Adams 2005).

Unlike in the typical Cobb-Douglas production estimation, in this article $K_{t}$ and $L_{t}$ series were generated out of the disposable income $\left(Y_{D t}\right)$ not the aggregate output (i.e. GDP) and expressed as $Y_{D t}=K_{t}^{\alpha_{1}} L_{t}^{1-\alpha_{1}}$. A typical Cobb-Douglas production function exhibits constant returns to scale. But in this article, the Cobb-Douglas production has decreasing returns to scale.

The Cobb -Douglas production function is used in evaluating the effect of human capital on economic growth. The relationship between human capital and output can be expressed by $Y_{t}=A_{t}^{\rho} H_{t}^{\gamma}$, where $H$ is the human capital index and $\rho, \gamma$ denote the respective parameters. In this article, attempts are made to test the theory that human capital growth spurs technological progress in the long run through 
its positive effects on economic growth. In order to evaluate this claim, this article employs the production model given by $A_{t}=H_{t}^{\varnothing} K_{p t}^{\alpha} L_{t}^{\beta}$, where $\varnothing$ is the elasticity for human capital, $K_{p t}$ is the capital productivity and $L_{p t}$ is the labour productivity.

\section{Description of relevant theoretical models}

The general form of the Cobb-Douglas production function that is commonly used in theoretical and empirical works is given by

$Y_{t}=A_{t} K_{t}^{\alpha} L_{t}^{\beta}$,

[Eqn 1]

where $A_{t}$ is overall level of technology in the national (or domestic) economy; $0<\alpha<1,0<\beta<1$ are parameters of returns to scale; $K_{t}$ is the amount of capital; $L_{t}$ is the amount of labour used to produce output $Y_{t}$ and $t$ denotes particular years. In this particular study, $t=1971,1972, \ldots . .2014$.

The average product (i.e. productivity) of a variable input, say capital productivity $\left(K_{p t}\right)$, is defined as the total output $\left(Y_{t}\right)$ divided by the amount of variable input $\left(K_{t}\right)$ and is given by

$K_{p t}=Y_{t} K_{t}^{-1}$.

[Eqn 2]

Similarly, labour productivity $\left(L_{p t}\right)$ is the total output $\left(Y_{t}\right)$ divided by the amount of labour and is given by

$L_{p t}=Y_{t} L_{t}^{-1}$

[Eqn 3]

It can be discerned from Equations (2) and (3) that in the short run, that is, when dealing with one input with respect to output, the influence of productivity of a variable input on output is positive, but the effect of productivity of a variable input on the amount of a given output is negative in the long run as depicted in Equation (4). The study is not dealing with the short-run effect of productivity on output, but with its long-run effect on total output (i.e. total physical product, implying the GDP).

Substituting Equations (2) and (3) in Equation (1) provides Equation (4), an expression for total aggregate output $\left(Y_{t}\right)$ expressed by

$Y_{t}=\left[A_{t} K_{p t}^{\alpha} L_{p t}^{\beta}\right]^{1 /(1-\alpha-\beta)}$.

[Eqn 4]

Equation (4) implies that other things are constant, for example, the political situation is stable, growth in level of technology has a positive influence on economic growth, whereas growth in either labour productivity or capital productivity has a negative effect on economic growth. That is because the economy is operating within the feasible region of production with decreasing returns to scale, that is, $0<\alpha+$ $\beta<1$, meaning that the value of $\alpha+\beta$ is always positive and lies between 0 and 1 .

\section{Estimation of the relevant variables: Capital, labour and technology}

In this section, the short-run (i.e. the period where only one input is utilised) relationship between output as disposable income and capital is specified in terms of the annual aggregate output that the households produce by employing $K$ units of capital to produce aggregate income $Y_{D}$ and is given by:

$Y_{d t}=\alpha_{1} K_{t}$

where $\alpha_{1}$ is a parameter, that is, the coefficient on capital (Alani 2016).

Differentiating Equation (5) with respect to capital (K) provides:

$d Y_{d t}=\alpha_{1} d K_{t}$

But

$d K_{t}=I_{t}$

As current capital stock is a function of level of current investment and is given by $K_{t}=K_{t-1}+I_{t}$, dividing Equation (5) in Equation (6) and manipulating the outcome yields:

$K_{t}=\frac{I_{t} Y_{d t}}{\partial Y_{d t}}$

Therefore, in period $t=2$, the value of $K_{2}$ is given by:

$K_{2}=\frac{I_{2} Y_{d 2}}{Y_{d 2}-Y_{d 1}}$.

Hence, after getting the value of $\alpha$, capital stock series in year 2 was calculated by using Equation (9). Consequently, the rest of the capital stock at a given time $t$ (i.e. within a given year) was estimated by:

$K_{t}=K_{t-1}+I_{t}$

[Eqn 10]

The estimate of the quantity of labour at a particular time $\left(L_{t}\right)$ was derived from the homogenous Cobb-Douglas production function and obtained using the formula:

$L_{t}=\left(\frac{Y_{d t}}{K_{t}^{\alpha_{1}}}\right)^{1 /\left(1-\alpha_{1}\right)}$

After regression of output level $\left(Y_{D t}\right)$ on quantities of capital stock $\left(K_{t}\right)$ and labour stock $\left(L_{t}\right)$ and obtaining the parameters $\alpha$ and $\beta$, the level of technology $\left(L_{t}\right)$ at time $t$ was estimated by using the formula:

$A_{t}=\frac{Y_{t}}{K_{t}^{\alpha} L_{t}^{\beta}}$.

[Eqn 12]

Finally, the value of human capital was estimated by HCI and is defined as the hypotenuse of the labour and capital vectors expressed as:

$H_{t}=\frac{\sqrt{K_{t}^{2}+L_{t}^{2}}}{\sqrt{K_{t-2}^{2}+L_{t-2}^{2}}}$. 


\section{Presentation of core econometric models of the study}

The core econometric models used in evaluating the role of human capital in promotion of technological progress were basically three.

The first econometric model for making empirical investigation expresses the influence of human capital and technological progress on output. This econometric equation could be used to empirically evaluate (i.e. determine) the role played by growth in human capital $(H)$ and technology $(A)$ in the promotion of growth in output $(Y)$ and may be presented as:

$Y_{t}=A_{t}^{\beta 1} H_{t}^{\beta 2} e^{u t}$.

[Eqn 14]

The second econometric model for empirical evaluation expresses the role played by human capital, labour productivity and capital productivity in the promotion of technological progress and is expressed as:

$$
A_{t}=H_{t}^{\beta 1} K_{p t}^{\beta 2} L_{p t}^{\beta} e^{u t}
$$

The third econometric model expresses the relationship between human capital and output that could be used to empirically evaluate (i.e. determine) the role played by technological progress in the promotion of economic growth, as well as the role played by physical capital $(K)$ and labour $(L)$ in the promotion of economic growth and is expressed as:

$Y_{t}=A_{t}^{\beta 1} K_{t}^{\beta 2} L_{t}^{\beta 3} e^{u t}$.

[Eqn 16]

In the econometric models above, $u t$ is the stochastic variable (i.e. random or disturbance term). For statistical estimation, the three equations may be expressed conveniently in log form. To have a deeper evaluation (i.e. analysis) of interactions among variables considered, more models were built in the way the three models above have been presented and statistically estimated.

\section{The generalised least squares estimation method}

Generalised least squares estimation is an efficient method for estimating the unknown coefficients of a linear regression model when the observations have unequal variance and there is a certain degree of correlation between the observations. The GLS estimates are equivalent to applying ordinary LS to a linearly transformed form of the data. The transformed form of the data is always uncorrelated, with constant variance (Kantar 2015). The transformed variables are used in weighted multiple linear regression (WREG) to estimate WREG. As a result, any of the least squares regression approaches, ordinary least squares (OLS), weighted least squares (WLS) or GLS (Eng, Chen \& Kiang 2009), is capable of producing estimators that are BLUE (i.e. best linear unbiased estimators). The procedure of transforming the original variables such that the transformed variables satisfy the assumptions of the classical model and then applying OLS to them is known as the GLS method. In a nutshell, GLS is OLS with transformed variables that can satisfy the standard least squares assumptions. After regressing the transformed variables, the estimators thus obtained are known as GLS estimators, and it is these estimators that are BLUE (Gujarati 2004:296).

If the sample is ordered in the models, then $\log \left(X_{i}\right)$ is also ordered. As a result, the covariance matrices of the dependent variable of these models are not in the form $\sigma^{2} I$, but of the form $\sigma^{2} T=\sum$, where $\sigma^{2}$ is unknown and $T$ is known (Engeman \& Keefe 1982; Kantar 2015; White 1969). Thus, the LS estimates of the coefficients may not have minimum variance. Therefore, in such cases, alternative estimation methods to stabilise variances can be used.

If a linear regression model is given by $Y_{i}=\beta_{0}+\beta_{1} X_{i}$. Then, the variance of $Y=Y_{1}, \ldots, Y_{n}$ is $\sigma^{2} T=\sum$ and the GLS minimises $(Y-X \beta)^{\prime} T^{-1}(Y-X \beta)$. The above expression can then be solved by $\hat{\beta}_{G L S}=\left(X^{\prime} T X\right) X^{\prime} T^{-1} Y$, where $\hat{\beta}_{G L S}$ is the vector of the GLS estimates of $\beta=\left(\beta_{1}, \beta_{2}\right)$ and $X$ is the matrix of ones and $x_{i}$. Also the GLS estimates are equivalent to applying ordinary LS to a linearly transformed form of the data.

This implies that we can write $T=P P^{\prime}$, where $P$ is a triangular matrix, using Cholesky decomposition. The least squares estimates calculated by regressing $P^{-1} Y$ on $P^{-1} X$ are equal to the GLS estimates. Thus, $\operatorname{Var}\left(P^{-1} Y\right)=P^{-1} \operatorname{Var}(Y)\left(P^{-1}\right)^{\prime}=\sigma^{2} I$, and, consequently, the transformed data set is uncorrelated, with constant variance (Kantar 2015).

\section{Data sources, types and data analysis}

This study uses secondary data to examine the effects of human capital on economic growth in Kenya by using annual time series data from 1970 to 2014. It performs the investigations on behaviour of real gross domestic product $(Y)$ in relation to human capital $(H C)$, level of technology $(A)$, quantity of capital stock $(K)$, amount of labour $(L)$, capital productivity $(K p)$, labour productivity $(L p), \mathrm{HCI}(H)$, household consumption $(\mathrm{Cn})$, investment spending $(I)$ and disposable income $(Y d)$. The secondary data were obtained from United Nations. Before conducting data analysis, all the variables were transformed into the natural log and differenced either once or twice. All the unit root tests were performed at $1 \%$ level of significance.

When the unit root tests were conducted, no variable was found to be stationary. After differencing once, all the variables were found to have I(1) order of co-integration except GDP $(Y)$ and capital stock $(K)$, which were found to have $\mathrm{I}(2)$ order of co-integration. Therefore, to avoid making spurious regressions, all the regressions were conducted appropriately after differencing the selected variables once or twice.

In the study, all the regressions were found to be adequate for drawing conclusions as follows: Firstly, by using the Durbin-Watson statistic, all the regression results were found to be free from serial correlation. Secondly, by employing the Koenker Bassett (KB) test for heteroskedasticity, all the regression results were found to have constant variance. 
Thirdly, the F-test revealed that in each of the regression results, the independent variables had joint effects on the respective dependent variables. The $t$-test statistic results indicated that in each and every regression result reported, the coefficients of independent variables were all significantly different from zero, implying that each of the individual variables could have influenced the independent variables in question.

Generally, as it can be verified from the list of Table of Regressions, all the regression results had very high R2 goodness of fit, implying that generally all the linear regression lines obtained could almost entirely explain variations in the movements of dependent variables considered within the given study period.

\section{Results}

After real disposable income was regressed on capital stock, the results showed that a $1 \%$ growth in capital could have caused disposable income to grow by $0.23 \%$ per annum ceteris paribus, as given by the linear regression Equation (17).

$\begin{array}{lll}D(Y D) & = & 0.23 D(K) \\ t & = & 9.94 \\ N=43 & R^{2}=0.507 & D W=1.74\end{array}$

[Eqn 17]

Equation (17) was used to determine the rate of change in capital stock on disposable income in Kenya between 1972 and 2014. The implication of this regression is that in Kenya, a unit change in capital could have caused disposable income to change by 0.23 of a unit, ceteris paribus. The coefficient value of 0.23 was used in the estimation of the labour stock series by using disposable income and capital stock series according to Equation (17).

Having calculated the labour stock series, the real income was regressed on capital stock and labour stock. Equation (18) reveals the effects of change in capital and change in labour stock on change in output in the economy of Kenya between 1972 and 2014.

Results from this regression revealed that in Kenya, within the given period, change in capital stock and labour stock by $1 \%$ could have led to $0.141 \%$ and $0.381 \%$ change in output, respectively, ceteris paribus, as portrayed by the regression Equation (18).

$$
\begin{array}{lll}
D(Y)= & 0.141 D(K) & +0.381 D(L) \\
t= & 8.044 & 4.268 \\
N=43 & R^{2}=0.714 & D W=1.952 \quad F=102.41
\end{array}
$$

[Eqn 18]

Equation (19) reveals that technology, capital and labour might have caused economic growth in Kenya between 1973 and 2014.

Thus, growth in labour force could have affected economic growth more than twice as much as growth in capital might have caused economic growth, in that a $1 \%$ growth in technology, capital and labour was associated with 1.0\%,
$0.14 \%$ and $0.38 \%$ growth in output, respectively, ceteris paribus. This kind of macroeconomic behaviour is very common in developing countries.

$$
\begin{array}{lccc}
\log Y= & 1.000 \log A & +0.141 \log K & +0.381 \log L \\
t= & 1038022.0 & 256670.0 & 755947.0 \\
N=42 & R^{2}=1.000 & D W=2.256 & F=1.72 \times 10^{11}
\end{array}
$$

[Eqn 19]

Growth in capital productivity, labour productivity, aggregate income and human capital by $1 \%$ could have caused technological progress by $0.07 \%, 0.37 \%, 0.49 \%$ and $0.14 \%$, respectively, as shown in Equations (20 and 21).

$$
\begin{array}{rlll}
\mathrm{d} \log A= & 0.485 d \log Y+0.069 d \log K p(-1) & +0.369 d \log L p[\text { Eqn 20] } \\
t= & 8.044 & 4.268 & 0.141 \\
& \mathrm{~N}=42 & R^{2}=984 \mathrm{DW}=2.027 F=1236
\end{array}
$$

Equation (21) reveals that $1 \%$ growth in human capital and labour productivity could have resulted in $0.139 \%$ and $0.379 \%$ increase in technological progress, ceteris paribus, in Kenya between 1976 and 2014.

$$
\begin{aligned}
& \frac{d \widehat{d d \log A}}{d d d \log K p}=0.623+0.139 \frac{d d d \log H}{d d d \log K p}+0.379 \frac{d d d L p}{d d d K p} \quad \text { [Eqn 21] } \\
& t \quad=23.12 \quad 7.580 \quad 1512 \\
& N=39 \quad R^{2}=0.99999 \quad D W=1.89 \quad F=1182615
\end{aligned}
$$

But capital productivity and labour productivity were found to have had negative influence on economic growth as can be discerned from Equations (22, 23, 24 and 25).

Equation (22) depicts the effects of increase in level of technology, capital productivity and labour productivity on economic growth in Kenya between 1973 and 2014, where a $1 \%$ growth in technology, capital productivity and labour productivity might have caused $2.1 \%,-0.2 \%$ and $0.7 \%$ growth, respectively, ceteris paribus.

$$
\begin{aligned}
& d \log Y)=2.018 d \log A \quad 0.153 d \log K p(-1)-0.748 d \log L p \quad \text { [Eqn 22] } \\
& t \quad=43.03 \quad-3.950 \quad-3.950 \\
& N=42 \quad R^{2}=0.937 \quad D W=1.885 \quad F=290.06
\end{aligned}
$$

Equation (23) presents the influence of level of technology, capital productivity and labour productivity on aggregate output in Kenya between 1973 and 2014, where a 1\% growth in technology, capital productivity and labour productivity could have caused output to grow by $2.09 \%,-1.29 \%$ and $-0.8 \%$, respectively, ceteris paribus.

$$
\begin{array}{lllll}
\widehat{\log Y)} & 2.091 \log A & -1.294 \log K p & -0.797 \log L p & \text { [Eqn 23] } \\
t= & 3370333 & -52581.0 & -124998 \\
N=42 & R^{2}=1.000 & D W=1.992 & F=2.14 \times 10^{11} &
\end{array}
$$

Equation (24) shows the effects of technical change, change in human capital and change in labour productivity on change in output in Kenya between 1977 and 2014. More importantly, human capital formation was found to have had negative effects on the economic growth of Kenya between 1977 and 2014, as illustrated in Equation (24), where a 1 unit change in 
technology, human capital and labour productivity might have caused $2.86 \times 10^{6},-5.1 \times 10^{11}$ and $-3.6 \times 10^{10}$ units change in output, respectively. One of the reasons for this unique relationship could be the fact that human capital could have effected economic growth via growth in productivity.

$$
\begin{aligned}
& \frac{d d d\left(\frac{Y}{I}\right)}{d d C n}=2.855 \times 10^{6} \frac{d d d\left(\frac{A}{I}\right)}{d d C n}-5.09 \times 10^{11} \frac{d d d\left(\frac{H}{I}\right)}{d d C n}[\text { Eqn24] } \\
& -3.61 \times 10^{10} \frac{\left(\frac{d d L p(-1)}{I}\right)}{d d C n} \\
& \begin{array}{llll}
t & =28.154 & -14.159 & -8.018
\end{array} \\
& N=38 \quad R^{2}=0.994 \quad D W=1.978 \quad F=3004.6
\end{aligned}
$$

Equation (25) also portrays the effects of growth in (1) technological progress and (2) productivity of both labour and capital on economic growth in Kenya between 1974 and 2014, in which a $1 \%$ growth in each of the three variables could have caused output to grow by $2.09,-0.8$ and -1.29 , respectively.

$$
\begin{gathered}
\frac{\widehat{d \log Y}}{d \log C n}=2.091 \frac{d \log A}{d \log C n}-0.797 \frac{d \log L p}{d \log C n}-1.294 \frac{d \log K p}{d C n} \text { [Eqn 25] } \\
t \quad=30466 \quad-17055 \quad-17550 \\
\quad N=41 \quad R^{2}=1.000 \quad D W=1.844 \quad F=4.451 \times 10^{8}
\end{gathered}
$$

Growth in human capital, labour stock and capital stock were found to have had positive effects on economic growth, as depicted by Equations (19) and (26). Equation (26) shows that a $1 \%$ growth in human capital caused a 3.5\% growth in the stock of labour in Kenya between 1973 and 2014. This result also reveals that variations in human capital can explain much of the variation in quantity of labour.

$$
\begin{array}{lll}
\frac{\widehat{d \log L}}{d \log Y} & = & 3.487 \frac{d \log (H)}{d \log Y} \\
t & = & 5.24 \\
N=42 & R^{2}=0.346 & D W=1.897
\end{array}
$$

[Eqn 26]

From Equation (27), one may discern that human capital stock in turn could have had a very big contribution towards employment generation. Growth in human capital might have also come as a result of increase in broad human capital (i.e. capital plus labour dimensions of human capital), reduction in labour productivity and increase in capital stock, as a $1 \%$ growth in human capital was associated with $1.2 \%, 0.8 \%$ and $-1 \%$ growth in labour, respectively, ceteris paribus.

$$
\begin{aligned}
& d \log L=1.203 d \log H+0.787 d \log K-0.998 d \log L p \\
& t \quad=3.104 \quad 13.922 \quad-14.510 \\
& N=41 \quad R^{2}=0.930 \quad D W=1.828 \quad F=250.96
\end{aligned}
$$

[Eqn 27]

However, according to Equation (28), growth in human capital might have come as a result of deliberate investment costs incurred in education of labourers (i.e. human capital formation might have not been a free venture), as a $1 \%$ growth in inputs, labour productivity and capital productivity was associated with $1.1 \%,-0.9 \%, 0.4 \%$ and $0.9 \%$ growth in human capital, income, labour productivity and capital productivity respectively, ceteris paribus. It might have required a deliberate move to delay rapid economic growth in order to increase human capital formation.

$$
\begin{aligned}
& \widehat{d l o g \frac{H}{C n}}= 1.06 d \log \frac{K+L}{C n} \quad-0.90 d \log \frac{Y(-2)}{C n} \\
&+0.04 d \log \frac{L p(-2)}{C n}+0.94 \log \frac{K p(-2)}{C n} \\
& t \quad 33.520 \quad-31.444 \quad 4.3254 \quad 68.263 \\
& N=39 \quad R^{2}=0.996 \quad D W=1.782 \quad F=3183.7
\end{aligned}
$$

In turn, growth in human capital (i.e. human capital formation or investments in education) as well as technological progress might have caused growth in either labour or capital productivity as revealed by Equations (29 and 30).

Equation (29) represents the effects of human capital growth, capital accumulation and labour growth on growth in capital productivity in Kenya within the 1974 to 2014 period, where a $1 \%$ growth in technology, human capital, capital and labour might have caused capital productivity to grow by $1.06 \%$, $0.43 \%,-0.83 \%, 0.35 \%$ per annum, respectively, ceteris paribus.

$$
\begin{aligned}
& \frac{d \log \left(\frac{K p}{I}\right)}{d \log C n}=1.06 \frac{d \log \left(\frac{A}{I}\right)}{d \log C n}+0.43 \frac{d \log \left(\frac{H}{I}\right)}{d \log C n}-0.83 \frac{d \log \left(\frac{K}{I}\right)}{d \log C n} \\
& +0.35 \frac{d \log \left(\frac{L}{I}\right)}{d \log C n} \\
& \begin{array}{llll}
t & =69.39729 .340 & -103.9 & 29.414
\end{array} \\
& N=41 \quad R^{2}=0.9999 \quad D W=1.766 \quad F=136204
\end{aligned}
$$

Equation (30) depicts the effects of technological progress, growth in human capital, growth in capital and growth in labour stock on labour productivity in Kenya within the 1974 to 2014 period, in which a $1 \%$ growth in technology, human capital, capital and labour was associated with $1.06 \%, 0.43 \%$, $0.17 \%,-0.65 \%$ growth, respectively, ceteris paribus.

$$
\begin{array}{ll}
\frac{d \log \left(\frac{L p}{I}\right)}{d \log C n}=1.06 \frac{d \log \left(\frac{A}{I}\right)}{d \log C n}+0.43 \frac{d \log \left(\frac{H}{I}\right)}{d \log C n} \\
\\
+0.17 \frac{d \log \left(\frac{K}{I}\right)}{d \log C n} \quad-0.65 \frac{d \log \left(\frac{L}{I}\right)}{d \log C n} \\
t \quad=69.31029 .298 \quad 20.772 \quad-54.945 \\
N=41 \quad R^{2}=0.9999 \quad D W=1.772 F=87760
\end{array}
$$


Technological progress could have resulted in rapid capital accumulation, but growth in capital productivity or labour might have caused reduction in capital accumulation as could be discerned from Equations (31 and 32), in which a $1 \%$ increase in technology, capital productivity and labour productivity was associated with $2.1 \%,-1.3 \%$, $-0.8 \%$ growth in output per annum, respectively, ceteris paribus.

$$
\begin{array}{llll}
\frac{d \log (Y)}{d \log C n}=2.091 \frac{d \log (A)}{d \log C n} & -1.294 \frac{d \log (K p)}{d \log C n} & -0.797 \frac{d \log (L p)}{d \log C n} \\
t & =10137 & -25703 & 5674 \\
N=41 & R^{2}=1.000 & D W=2.305 & F=4.451 \times 10^{8}
\end{array}
$$

Equation (32) illustrates the fact that a 1 unit change in output, capital productivity, and labour productivity was associated with $4.17,-4.4 \times 10^{12}, 5.7 \times 10^{11}$ units change in capital stock per annum, respectively, ceteris paribus, in Kenya between 1975 and 2014. Equation (32) implies that in the short run capital productivity has a positive influence on economic growth and labour productivity.

$$
\begin{aligned}
& \frac{\overline{d(d(K / I))}}{d(d(C n))}=4.173 \frac{d(d(Y / I))}{d(d(C n))} \quad-4.38 \times 10^{12} \frac{d(d(K p / I))}{d(d(C n))} \\
& +5.72 \times 10^{11} \frac{d(d((L p / I))}{d(d(C n))} \\
& \begin{array}{llll}
t & =18.764 & -3.566 & 3.071
\end{array} \\
& N=40 \quad R^{2}=0.988 \quad D W=1.698 \quad F=1466.2
\end{aligned}
$$

[Eqn 32]

Similarly, technological progress might have promoted capital formation, but capital productivity or labour productivity might have caused reduction in employment in Kenya within the given period as can be observed from Equations (33) and (34), in which a $1 \%$ increase in technology, capital productivity and labour productivity was associated with $2.1 \%,-1.3 \%$ and $-0.8 \%$ growth in capital accumulation, respectively.

$$
\begin{array}{llll}
\frac{\widehat{d \log (K)}}{d \log C n}=2.091 \frac{d \log (A)}{d \log C n} & -1.294 \frac{d \log (K p)}{d \log C n} & -0.797 \frac{d \log (L p)}{d \log C n} \\
t & =21004 & -12103 & -26511 \\
N=41 & R^{2}=1.000 & D W=2.31 & F=4.2 \times 10^{8}
\end{array}
$$

It can be observed from Equation (34) that economic growth and capital productivity growth had positive consequences on labour generation, but growth in labour productivity had negative effects on labour generation in Kenya between 1974 and 2014, where a 1\% growth in technology, capital productivity and labour productivity was associated with $2.1 \%,-0.29 \%$ and $-1.8 \%$ growth per year, respectively, ceteris paribus.

$$
\begin{aligned}
& \frac{d(d(L))}{d(d(C n))}=2.091 \frac{d(d(A))}{d(d(C n))}-0.294 \frac{d(d(K p))}{d(d(C n))}-1.797 \frac{d(d((L p))}{d(d(C n))} \\
& \begin{array}{llll}
t & =12.17 & 3.922 & -2.719
\end{array} \\
& N=41 \quad R^{2}=1.000 \quad D W=1.748 \quad F=1.91 \times 10^{8}
\end{aligned}
$$

[Eqn 34]

Technological progress and promotion of human capital formation (i.e. increased human capital and labour) by 1 unit change could have resulted in rapid capital accumulation by $1.21,6.9 \times 10^{12}$ and 4.5 units per year, respectively, ceteris paribus, as illustrated in Equation (35):

$$
\begin{array}{rlrl}
\frac{d(d(K / Y))}{d(d(C n))}= & 12071196 \frac{d(d(A / Y))}{d(d(C n))}+6.94 \times 10^{11} \frac{d(d(H / Y))}{d(d(C n))} \\
& +4.51 \frac{d(d((L / Y))}{d(d(C n))} & & \\
t & =12.13 & 6.644 & 13.044 \\
N=40 & R^{2}=0.997 & D W=1.884 & F=785.77
\end{array}
$$

[Eqn 35]

Finally, the first conclusion that this article makes is that human capital played a positive role in promotion of technological progress in Kenya between 1976 and 2014, as illustrated in Equation (36). Equation (36) also empirically establishes the fact that productivity of either capital or labour had positive consequences on technological progress in Kenya between 1976 and 2014. These two conclusions are backed by the fact that a $1 \%$ growth in human capital and capital productivity and labour productivity was associated with $0.16 \%, 0.61 \%$ and $0.37 \%$ increase in technological progress per annum, respectively, ceteris paribus.

$$
\begin{aligned}
& \frac{d \widehat{d d \log A}}{d d d \log A(-1)}=0.161 \frac{d d d(H)}{d d d \log A(-1)}+0.611 \frac{d d d \log K p}{d d d \log A(-1)} \\
& +0.369 \frac{d d d \log L p}{d d d \log A(-1)} \\
& \begin{array}{llll}
t & 6.073 & 59.157 & 52.593
\end{array} \\
& N=39 \quad R^{2}=0.992 \quad D W=2.175 \quad F=2292.9
\end{aligned}
$$

[Eqn 36]

The second conclusion this article makes is that human capital played a positive role in the promotion of economic growth and development in Kenya between 1975 and 2014, as portrayed by Equation (37). Also, from Equation (37), one can discern that technological progress likewise played a significant role in spurring economic growth in Kenya between 1975 and 2014. These two statements are confirmed by the fact that a $1 \%$ rise in technology and human capital was associated with $1.54 \%$ and $2.09 \%$ increase in economic growth per annum, respectively, ceteris paribus. 


$$
\begin{aligned}
& \frac{d(\log (Y)}{d\left(d\left(\log \left(\frac{Y d}{C n}\right)\right)\right)}=1.536 \frac{d(\log (A))}{d\left(d\left(\log \left(\frac{Y d}{C n}\right)\right)\right)} \\
& +2.091 \frac{d(\log (H))}{d\left(d\left(\log \left(\frac{Y d}{C n}\right)\right)\right)} \\
& t \quad=25.456 \quad 4.261 \\
& N=40 \quad R^{2}=0.945 \quad D W=1.894 \quad F=650.1
\end{aligned}
$$

[Eqn 37]

\section{Discussion}

This article reveals that human capital played a positive role in the promotion of economic growth in Kenya between 1970 and 2014. It found that a $1 \%$ increase in human capital measured in broad terms was associated with a $1.2 \%$ annual increase in economic growth in Kenya within the given period. Other past studies arrived at a similar conclusion. For instance, Barro (1991) used data for 98 countries from 1960 to 1985 and related the real growth rate of GDP per capita to initial human capital, with school enrolment rates of 1960 as a proxy. The research found that output growth was significantly positively determined by both primary and secondary school enrolment, in the presence of other determinants. A $1 \%$ point increase in primary school enrolment was associated with a $2.5 \%$ increase in GDP growth and a similar increase in secondary school enrolment produced 3\% growth.

Gemmell (1996) used OECD data sets and measured human capital in terms of both stocks and annual average growth rates at primary, secondary and tertiary education levels. He found that a $1 \%$ increase in initial tertiary human stock was associated with a $1.1 \%$ increase in per capita GDP growth. But a $1 \%$ increase in subsequent growth in tertiary education (flow) was associated with almost $6 \%$ output growth. Barro and Lee (1993) employed the average years of secondary schooling as a key explanatory variable. Their results suggested that an extra year of male secondary schooling was associated with a $1.4 \%$ increase in GDP growth per worker. Barro (1997) applied a more sophisticated estimating technique and found that an extra year of male upper-level schooling was associated with a $1.2 \%$ increase in per capita GDP growth rate. Judson (1998) employed UNESCO data on educational enrolments and spending, and found that a $1 \%$ increase in human capital growth was associated with an $11 \%$ increase in GDP growth rate. Generally, evidence suggests that a $1 \%$ increase in school enrolment rates led to an increase in GDP per capita growth of between $1 \%$ and 3\%. Moreover, a 1\% increase in human capital in terms of additional year of secondary education led to more than a $1 \%$ increase in economic growth each year (Wilson \& Briscoe 2004).

Lastly, this article evaluates the role played by human capital in the promotion of technological progress in Kenya between
1970 and 2014. This article found that a 1\% growth in human capital in Kenya was associated with $0.43 \%$ rise in technological progress. Other researchers arrived at a similar finding. For instance, Lopez-Pueyo, Barcenilla and Gimenez (2016) found that human capital acted as a catalyst of technological diffusion from the leader. Thus, human capital drives domestic innovation and promotes a country's capabilities to take advantage of its backwardness (LopezPueyo et al. 2016; Nelson \& Phelps 1966; Romer 1990). Human capital is also a catalyst of technological diffusion and is an estimate of an economy's capacity for domestic innovation and technology adoption from abroad (Benhabib \& Spiegel 2005).

\section{Conclusion}

In this article, human capital is measured in terms of $\mathrm{HCI}(\mathrm{H})$ in the national economy, and when the data set for the broad HCI estimate was subjected to GLS regressions, it outperformed all the other measures of human capital by yielding very good regression results. In Kenya, growth in capital productivity, labour productivity, aggregate income and human capital could have had positive effects on technological progress. But capital productivity and labour productivity were found to have had negative influence on economic growth. Growth in human capital, labour stock and capital stock were found to have had positive effects on economic growth. Human capital is one of the most important factors for national economic growth in the modern economy.

The study defines human capital in a broad sense and estimates human capital through the aggregate stock of labour and physical capital. This is because in the concept of human capital the human is viewed both as human the labour force and human the creator. Thus, this article treats education as an investment in man and treats its consequences as a form of capital. The human capital is a fundamental source of economic productivity. Investment in humans can cause them to increase their productivity in two ways. One of the ways is technological progress and the other is rapid production of goods and services. This article, therefore, finds that through increase in productivity, human capital formation affects output in two ways.

In one way, increased technological progress is good for bringing about rapid capital accumulation and economic growth. In the other way, increased productivity in either capital or labour is detrimental to employment generation and capital accumulation, resulting in economic decline. This is because increase in capital productivity causes some capital to lie idle, and increase in labour productivity causes some labour hours as well as labourers to be squeezed out of the productive process.

That is, future productivity growth ends up depleting current capital stock, labour stock and output because presumably economic growth can only be improved at a cost. Hence, this 
article discovers that although technical progress and human capital formation are very good for physical capital accumulation, they are mainly responsible for squeezing out labour from the production process. Thus, a nation undertaking rapid economic growth has to put in an inbuilt synergistic mechanism for compensation because labourers might be squeezed out of the production process.

\section{Recommendations}

The results suggest the following:

- An important role for the technological progress through (a) acquisition, (b) innovation and (c) diffusion of technology.

- An important role for investment in human capital in terms of improvement in knowledge acquisition, health, security and so on.

- An important role for economic development through better development and technology strategies, management, policies and plans that must reflect adequate support for human capital building.

- An important role for further research on the role of human capital in the promotion of technological progress, economic growth and development in order to find ways and means of attaining rapid economic growth through advancing technology and human capital.

- An important role for capital accumulation and labour generation because these two variables constitute the human capital base.

- An important role for constituting and implementing the human intellectual capital laws necessary for rapid human capital and technology development.

- An important role for both the technology and human capital development to be linked to feasible investment schemes in all sectors of the economy geared towards maximising job creation and employment.

- An important role for replication (i.e. imitation) of successful experience from countries that have benefited most from human capital and technology development to achieve rapid economic growth.

- An important role for providing adequate resources to the ministry of education and the ministry of science and technology.

- An important role for deliberate establishment of a technology resource and development centre for agricultural industries and non-agricultural industries.

- An important role for supporting individuals who are engaged in technology and human development programmes and projects.

- An important role for stakeholders, experts, government, non-governmental organisations (NGOs) and investors involvement in the promotion of technical progress, human capital investments and economic development.

- An important role for deliberate transfer of technology from the developed world to the developing world with an agenda of environmental protection.

- An important role for introducing industrial parks that are necessary for job creation as well as for technology and human capital development.

\section{Acknowledgements}

I acknowledge the African Evaluation Journal for making my manuscript achieve scholarly excellence.

\section{Competing interests}

I declare that I have no financial or personal relationships that may have inappropriately influenced me in writing this article.

\section{References}

Alani, J., 2016, 'Human capital and economic growth in Uganda', Unpublished pape presented at 2016 Africa Meeting of Econometric Society in Protea Hotel Kruger Gate, Mpumalanga, South Africa, 25-28th July.

Alika, I.J. \& Aibieyi, S., 2014, 'Human capital: Definitions, approaches and management dynamics', Journal of Business Administration and Education 5(1), 55-78.

Barro, R.J., 1991, 'Economic growth in a cross-section of countries', Quarterly Journa of Economics 106(2), 407-443. https://doi.org/10.2307/2937943

Barro, R.J., 1997, Determinants of economic growth: A cross-country empirical study, MIT Press, Cambridge, MA

Barro, R.J. \& Lee, J.W., 1993, 'International comparisons of educational attainment', Journal of Monetary Economics 32(3), 363-394. https://doi.org/10.1016/03043932(93)90023-9

Becker, G.S., 1993, Human capital: A theoretical and empirical analysis with specia reference to education, 3rd edn., University of Chicago Press, Chicago, IL.

Benhabib, J. \& Spiegel, M.M., 2005, 'Human capital and technology diffusion', in P. Aghion \& S.N. Durlauf (eds.), Handbook of Economic Growth, 1A, pp. 935-966, Elsevier, North-Holland.

Boldizzoni, F., 2008, Means and ends: The idea of capital in the west; 1500-1970, Palgrave Macmillan, New York.

Coleman, J.C., 1993, 'The impact of Becker, Gary on sociology', Acta Sociologica 36(3), 169-178. https://doi.org/10.1177/000169939303600302

Eggoh, J., Houeninvo, H. \& Sossou, G.A., 2015, 'Education, health and economic growth in African countries', Journal of Economic Development 40(1), 93-111.

Eng, K., Chen, Y.Y. \& Kiang, K.E., 2009, User's guide to the Weighted Multiple Linear Regression Program (WREG Version 1.0): U.S. geological survey techniques and methods, book 4, chap. A8, p. 21, viewed n.d., from http://pubs.usgs.gov/tm/ tm4a8

Engeman, R.M. \& Keefe, T.J., 1982, 'On generalized least squares estimation of the Weibull distribution', Communications in Statistics-Theory and Methods 19 (11) 2181-2193. https://doi.org/10.1080/03610928208828380

Farr, W., 1853, 'Equitable taxation of property', Journal of Royal Statistics 16, 1-45.

Felipe, J. \& Adams, F.G., 2005, 'The estimation of the Cobb-Douglas function: A retrospective view', Eastern Economic Journal 36(3), 427-445.

Gemmell, N., 1996, 'Evaluating the impacts of human capital stocks and accumulation on economic growth: Some new evidence', Oxford Bulletin of Economics and Statistics 58(1), 9-28. https://doi.org/10.1111/j.1468-0084.1996.mp58001002.x

Gujarati, D.N., 2004, Basic econometrics, 4th edn., McGraw-Hill Companies, New York.

Healy, T., 1998, Counting human capital, Organisation for Economic Cooperation and Development, The OECD Observer, Issue 212, Paris, pp. 31-33.

Jones, L. \& Manuelli, R., 1990, 'A convex model of equilibrium growth: Theory and policy implications', Journal of Political Economy 98(5), 1008-1038. https://doi. org $/ 10.1086 / 261717$

Judson, R., 1998, 'Economic growth and investment in education: How allocation matters', Journal of Economic Growth 3(4), 337-360. https://doi. org/10.1023/A:1009763906365

Kantar, Y.M., 2015, 'Generalized least squares and weighted least squares estimation methods for distributional parameters', REVSTAT Statistical Journal 13(3), 263282.

Kiker, B.F., 1966, 'The historical roots of the concept of human capital', Journal of Political Economy 74(5), 481-499. https://doi.org/10.1086/259201

Kucharcikova, A., 2011, 'Human capital-definitions and approaches', Human Resources Management and Ergonomics 5(2), 60-70.

Kwon, D.B., 2009, 'Human capital and its measurement', The 3rd OECD World Forum on Statistics, Knowledge and Policy. Charting Progress, Building Visions, Improving Life Busan, Korea, 27-30th October.

Little, A.W., 2003, 'Motivating learning and the development of human capital', Journal Compare 33(4), 437-452. https://doi.org/10.1080/0305792032000127748

Lopez-Pueyo, C., Barcenilla, S. \& Gimenez, G., 2016, The two faces of human capital and their effect on technological progress, Research Paper Submitted to University of Zaragoza, Calle de Pedro Cerbuna, Spain.

Lucas, R.E., Jr, 1988, 'On the mechanics of economic development', Journal of Monetary Economics 22(1), 3- 42. https://doi.org/10.1016/0304-3932(88)90168-7 
Mincer, J., 1958, 'Investment in human capital and personal income distribution', Journal of Political Economy 66(4), 281-202. https://doi.org/10.1086/258055

Nelson, R.R. \& Phelps, E.S., 1966, 'Investment in humans, technological diffusion, and economic growth', The American Economic Review 56(1/2), 69-75.

Oxley, L., Le, T. \& Gibson, J., 2008, 'Measuring human capital: Alternative methods and international evidence', The Korean Economic Review 24(2), 283-344.

Petty, W., 1690, 'Political Arithmetik', in C.H. Hull (1899) (eds.), The Economic Writings of Sir William Petty, Chap. 1-10, Cambridge University Press, Cambridge.

Romer, P., 1986, 'Increasing returns and long run growth', Journal of Political Economy 94(5), 1002-1037. https://doi.org/10.1086/261420

Romer, P.M., 1990, 'Endogenous technological change', Journal of Political Economy 98(5), S71-S102. https://doi.org/10.1086/261725
Schultz, T.W., 1961, 'Investment in human capital', American Economic Review 51(1), $1-17$.

Schultz, T.W., 1971, 'Investment in human capital', in B.F. Kiker (ed.), Investment in human capital, pp. 1-8, University of South Carolina Press, Columbia.

Schulz, T.W., 1981, Investment in people: The economics of population quality, University of California Press, Berkeley, CA.

Smith, A., 1776, 'An inquiry into the nature and causes of the wealth of nations', W. Strahan and T. Cadell, London.

White, J.S., 1969, 'The moments of Log-Weibull order statistics', Technometrics 2(11), 373-386. https://doi.org/10.1080/00401706.1969.10490691

Wilson, R.A. \& Briscoe, G., 2004, The impact of human capital on economic growth: A review, European Center for the Development of Vocational Training (CEDEFOP) Reference Series 54, pp. 10-68, Office for Official Publications of the European Communities (CEDEFOP), Luxembourg. 